\title{
Ectopic Hepatocellular Carcinoma Arising from the Peritoneum in a Patient with a History of Oropharyngeal Cancer: A Case Report
}

\author{
Ji Young Lee Kwang Hee Kim $^{\mathrm{b}}$ Mi Seon Kang ${ }^{\mathrm{c}}$ Ki Hyang Kim ${ }^{\mathrm{a}}$ \\ ${ }^{a}$ Division of Hematology-Oncology, Department of Internal Medicine, and Departments of \\ ${ }^{b}$ General Surgery and 'Pathology, Busan Paik Hospital, Inje University College of Medicine, \\ Busan, South Korea
}

\section{Key Words}

Ectopic hepatocellular carcinoma $\cdot$ Ectopic liver

\begin{abstract}
A subphrenic mass was noted on a surveillance computed tomography (CT) scan of a 65year-old man who had achieved complete remission of oropharyngeal cancer after concurrent chemoradiotherapy. The mass was $3.2 \mathrm{~cm}$ in size and showed a multilobular enhancing pattern along the peritoneal lining. The patient was negative for hepatitis $B$ surface antigen and anti-hepatitis $C$ virus antibody. His carcinoembryonic antigen level was within the normal range. Contrast-enhanced $\mathrm{CT}$ revealed no mass in the liver. He underwent surgery, and a pale yellowish soft tumor measuring $3.8 \times 3.2 \times 1.2 \mathrm{~cm}$ was resected. Histologically, the tumor was confirmed to be a hepatocellular carcinoma. Currently, he is doing well, and has been followed up without any signs of recurrence.

(C) 2015 The Author(s)

Published by S. Karger AG, Basel
\end{abstract}

\section{Introduction}

Ectopic liver is a rare developmental anomaly. Collan et al. [1] classified liver abnormalities into 4 types, according to their sizes and connections to the liver: (1) ectopic liver, arising outside the liver and without connection to the liver; (2) microscopic ectopic liver, which is found occasionally in the wall of the gallbladder; (3) large accessory liver lobe attached to the liver by a stalk, (4) and small accessory liver lobe attached to the liver. Cases are usually 
Lee et al.: Ectopic Hepatocellular Carcinoma Arising from the Peritoneum in a Patient with a History of Oropharyngeal Cancer: A Case Report

asymptomatic and found incidentally. The incidence of ectopic liver has been reported to be $0.23-0.7 \%$ based on autopsy and laparoscopic studies [2, 3]. Here, we present a case of ectopic hepatocellular carcinoma which was diagnosed incidentally in a patient with a history of oropharyngeal cancer.

\section{Case Report}

A 65-year-old man with a 50-pack-year smoking history was diagnosed with squamous cell carcinoma of the left tonsil in August 2012. The stage of the disease was T3 N2 M0, and he underwent concurrent chemoradiotherapy with cisplatin from August 2012 to October 2012. The patient achieved complete remission after concurrent chemoradiotherapy. Subsequently, he received a head and neck examination, contrast-enhanced chest computed tomography (CT), and neck CT every 3 months for the purpose of surveillance. There was no evidence of malignancy during the first 10 months.

In September 2013, a peritoneal mass at the left subphrenic region was detected on chest CT. The mass was $3.2 \mathrm{~cm}$ in size and showed a multilobular enhancing pattern along the peritoneal lining (fig. 1). The patient did not have any symptoms. Physical examination and blood chemistry did not show any abnormal findings. He was negative for hepatitis B virus (HBV) surface antigen and anti-hepatitis $\mathrm{C}$ virus (HCV) antibody. His carcinoembryonic antigen level was within the normal range. $\alpha$-Fetoprotein (AFP) and protein induced by vitamin $\mathrm{K}$ absence or antagonist II levels were not measured. Contrast-enhanced CT revealed no mass in the liver.

The peritoneal mass was resected and found to be a $3.8 \times 3.2 \times 1.2 \mathrm{~cm}$ pale yellowish soft tumor. Visual inspection revealed no invasion to the diaphragm. Microscopically, the tumor showed large polygonal cells arranged in a trabecular or nodular pattern separated by sinusoid-like vessels (fig. 2). Tumor cells had eosinophilic or clear cytoplasm and hyperchromatic nuclei with prominent nucleoli. Immunohistochemical stains showed that the tumor cells were diffusely positive for hepatocyte antigen (fig. 3a), focally positive for AFP and cytokeratin, and negative for vimentin, synaptophysin, chromogranin, S-100, epithelial membrane antigen, and CD56. Several cytokeratin-positive bile ductules were noted at the peripheral portion of the tumor (fig. $3 \mathrm{~b}$ ), but the tumor did not contain liver parenchyma. These findings confirmed that the tumor was a hepatocellular carcinoma. Seventeen months after surgical resection, the patient is doing well, and there have been no signs of recurrence after the operation.

\section{Discussion}

The liver is derived from the outgrowth of the foregut endoderm, which is called 'the hepatic diverticulum', in the fourth week of gestation [4]. The hepatic diverticulum penetrates the septum transversum. The cephalic portion of the hepatic diverticulum lies within the septum transversum, is called 'the liver primordium', and gives rises to the liver. In some cases, liver tissue migrates to various organs during embryogenesis, which may explain the occurrence of ectopic liver. Ectopic liver can be detected at various sites in the body, including the gallbladder, spleen, retroperitoneum, pancreas, adrenal gland, portal vein, diaphragm, thorax, gastric serosa, testis, and umbilical vein [5].

Ectopic liver can cause unexpected clinical problems. Although hemangioma, adenoma, nodular hyperplasia, and other benign lesions may arise, malignancies are more frequent in 
Lee et al.: Ectopic Hepatocellular Carcinoma Arising from the Peritoneum in a Patient with a History of Oropharyngeal Cancer: A Case Report

cases of ectopic liver $[6,7]$. Some reports have noted that ectopic hepatocellular carcinoma can be observed in about $7-30 \%$ of cases of ectopic liver $[8,9]$. The carcinogenetic factors in ectopic liver are poorly understood. Common risk factors for hepatocellular carcinoma, such as HBV or HCV infection and cirrhosis, appear to be less relevant in cases of ectopic hepatocellular carcinoma. In a review of 22 cases of ectopic hepatocellular carcinoma, Arakawa et al. [9] reported positivity for HBV surface antigen or anti-HCV antibody in only 1 case each. Further, only 7 (32\%) of the 22 cases of ectopic hepatocellular carcinoma had developed in patients with cirrhosis in the mother liver. In contrast, the incidences of HBV infection, HCV infection, and liver cirrhosis among patients with hepatocellular carcinoma in Japan are $14.51,75$, and $80 \%$, respectively $[5,10]$. Some authors have suggested that the relatively high propensity to malignant transformation in the ectopic liver may relate to its incomplete functional architecture, such as for vascular or biliary drainage, which could induce a metabolic handicap and thereby facilitate carcinogenesis $[11,12]$.

In addition to being elevated in hepatocellular carcinoma of the mother liver, it is also possible for AFP to be elevated in ectopic hepatocellular carcinoma. A review of the literature reported that $63 \%$ of patients with ectopic hepatocellular carcinoma showed elevated AFP levels $>1,000 \mathrm{ng} / \mathrm{ml}$ [13-15]. Furthermore, there have been additional case reports of ectopic hepatocellular carcinoma with elevated AFP since the publication of that literature review [13-15]. Unfortunately, we did not measure AFP, and a preoperative diagnosis of hepatocellular carcinoma was not considered. It is difficult to suspect ectopic hepatocellular carcinoma as the primary diagnosis for an unknown intra-abdominal mass. Indeed, ectopic hepatocellular carcinoma is a very rare disease that does not have any specific signs or symptoms. In most cases, the diagnosis has been made based on postoperative histology, rather than preoperative imaging or biopsy [6]. When a heterogeneously enhanced intraabdominal mass is detected, ectopic hepatocellular carcinoma should be considered, and the measurement of AFP would help to establish the diagnosis.

In general, most clinicians who treat cases of ectopic hepatocellular carcinoma follow the same guidelines that are applied for hepatocellular carcinoma in the mother liver. We also treat our patients according to these guidelines, and we assess AFP and provide CT scans of the liver every 6 months after complete resection. Complete cure after surgery has been reported in many cases. Thirteen case reports have been published regarding patients with ectopic hepatocellular carcinoma who were alive and well at the most recent follow-up [6]. These tumors may be susceptible to curative resection. Furthermore, two case reports have described the administration of adjuvant chemotherapy after complete resection [12, 15], even though the American Association for the Study of Liver Disease Practice Guideline and The National Comprehensive Cancer Network Clinical Practice Guideline do not recommend adjuvant chemotherapy routinely.

In conclusion, we have reported a case of ectopic hepatocellular carcinoma arising from the peritoneum.

\section{Statement of Ethics}

Informed consent was obtained from the patient.

\section{Disclosure Statement}

The authors report no conflicts of interest related to this work. 


\section{Case Reports in Oncology}

\begin{tabular}{l|l}
\hline Case Rep Oncol 2015;8:456-460 \\
\hline DOI: 10.1159/000441020 & $\begin{array}{l}\text { C 2015 The Author(s). Published by S. Karger AG, Basel } \\
\text { www.karger.com/cro }\end{array}$ \\
\hline
\end{tabular}

Lee et al.: Ectopic Hepatocellular Carcinoma Arising from the Peritoneum in a Patient with a History of Oropharyngeal Cancer: A Case Report

\section{References}

1 Collan Y, Hakkiluoto A, Hastbacka J: Ectopic liver. Ann Chir Gynaecol 1978;67:27-29.

-2 Sato S, Watanabe M, Nagasawa S, Niigaki M, Sakai S, Akagi S: Laparoscopic observations of congenital anomalies of the liver. Gastrointest Endosc 1998;47:136-140.

3 Watanabe M, Matsura T, Takatori Y, Ueki K, Kobatake T, Hidaka M, et al: Five cases of ectopic liver and a case of accessory lobe of the liver. Endoscopy 1989;21:39-42.

4 Tan CE, Vijayan V: New clues for the developing human biliary system at the porta hepatis. J Hepatobiliary Pancreat Surg 2001;8:295-302.

5 Caygill CP, Gatenby PA: Ectopic liver and hepatocarcinogenesis. Eur J Gastroenterol Hepatol 2004;16:727729.

6 Kubota K, Kita J, Rokkaku K, Iwasaki Y, Sawada T, Imura J, et al: Ectopic hepatocellular carcinoma arising from the pancreas: a case report and review of the literature. World J Gastroenterol 2007;13:4270-4273.

7 Leone N, Saettone S, De Paolis P, Carucci P, Brunello F, De Angelis C, et al: Ectopic livers and related pathology: report of three cases of benign lesions. Dig Dis Sci 2005;50:1818-1822.

8 Seo UH, Lee HJ, Ryu WS, Kwak JM, Shin BK, Kim WB, et al: Laparoscopic resection of a hepatocellular carcinoma arising from an ectopic liver. Surg Laparosc Endosc Percutan Tech 2008;18:508-510.

-9 Arakawa M, Kimura Y, Sakata K, Kubo Y, Fukushima T, Okuda K: Propensity of ectopic liver to hepatocarcinogenesis: case reports and a review of the literature. Hepatology 1999;29:57-61.

10 Kiyosawa K, Umemura T, Ichijo T, Matsumoto A, Yoshizawa K, Gad A, et al: Hepatocellular carcinoma: recent trends in Japan. Gastroenterology 2004;127:S17-S26.

$\$ 11$ Kelly PJ, Spence R, Dasari BV, Burt AD, Taylor M, Loughrey MB: Primary hepatocellular carcinoma of the pancreas: a case report and review of the heterogeneous group of pancreatic hepatoid carcinomas. Histopathology 2012;60:1012-1015.

12 Zonca P, Martinek L, Ihnat P, Fleege J: Ectopic liver: different manifestations, one solution. World J Gastroenterol 2013;19:6485-6489.

13 Nakamura N, Irie T, Tanaka S, Arii S: A case of ectopic hepatocellular carcinoma with peritoneal dissemination. Nihon Shokakibyo Gakkai Zasshi 2013;110:1968-1975.

14 Kanzaki R, Yamada T, Gotoh K, Takahashi H, Ohigashi H, Ishikawa O: Ectopic hepatocellular carcinoma arising in the left triangular ligament of the liver. Case Rep Gastroenterol 2010;4:138-143.

15 Oldani A, Garavoglia M: Hepatocellular cancer arising from ectopic liver tissue on diaphragm. Case report. Ann Ital Chir 2014;85:pii:S2239253X14022622.

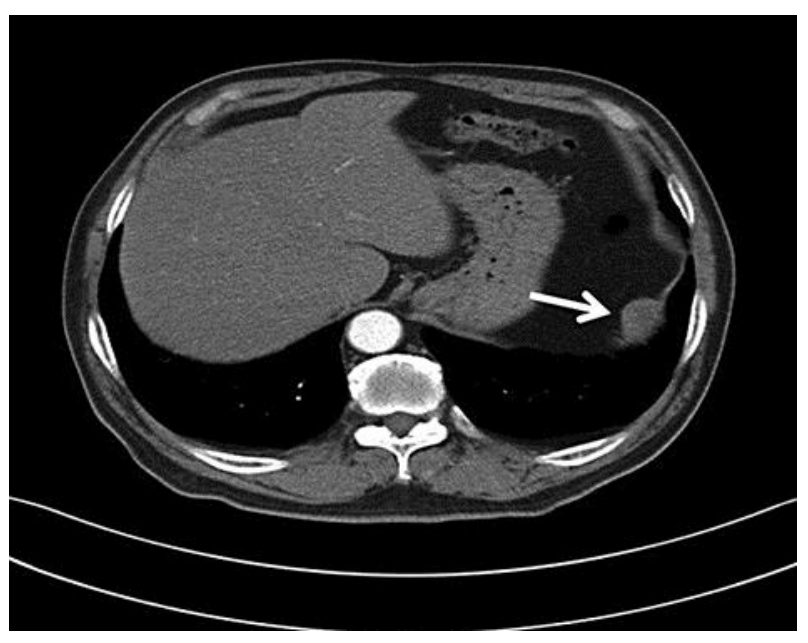

Fig. 1. As seen in this chest CT scan, the tumor is located in the left subphrenic area (arrow) and shows a multilobular enhancing pattern along the peritoneal lining. 


\section{Case Reports in Oncology}

\begin{tabular}{l|l}
\hline Case Rep Oncol 2015;8:456-460 \\
\hline DOI: 10.1159/000441020 & $\begin{array}{l}\text { ○ } 2015 \text { The Author(s). Published by S. Karger AG, Basel } \\
\text { www.karger.com/cro }\end{array}$ \\
\hline
\end{tabular}

Lee et al.: Ectopic Hepatocellular Carcinoma Arising from the Peritoneum in a Patient with a History of Oropharyngeal Cancer: A Case Report

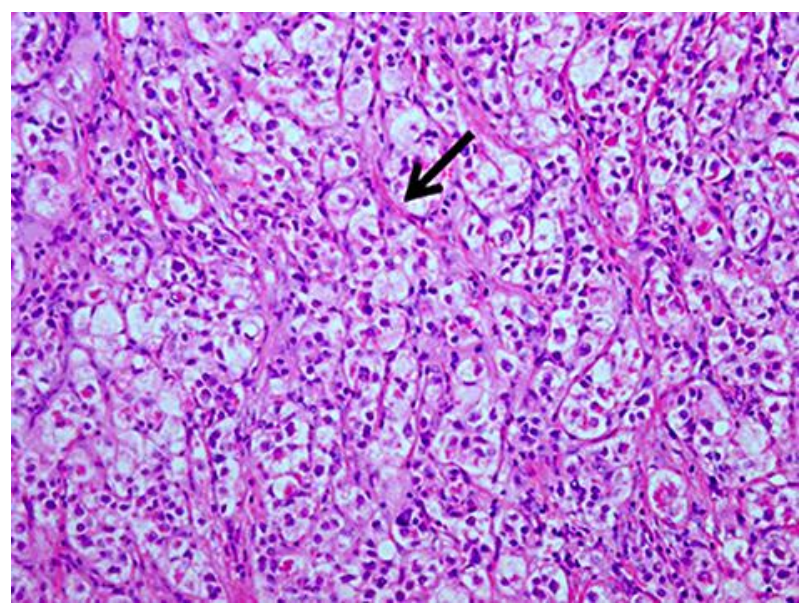

Fig. 2. The tumor cells are arranged in a trabecular pattern with sinusoid-like vessels (arrow). H\&E. $\times 200$.

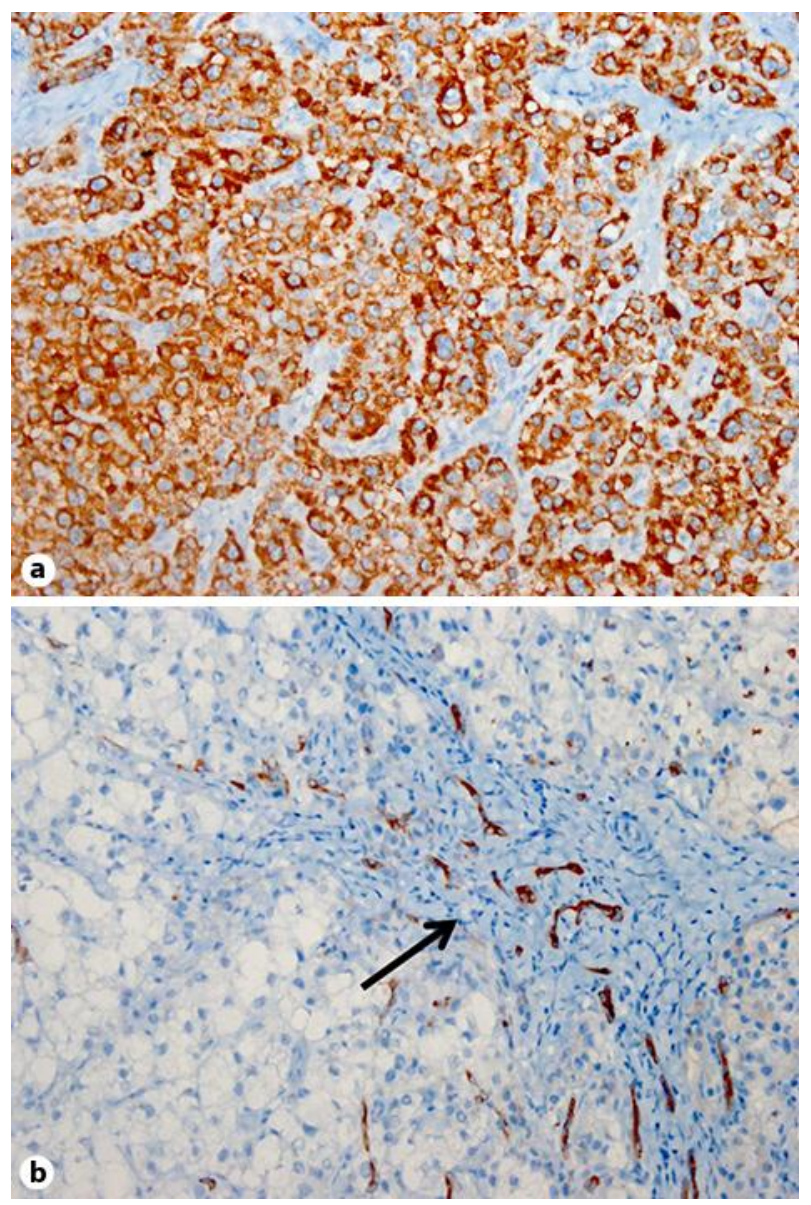

Fig. 3. Tumor cells express antihuman hepatocyte antigen $(a, \times 100)$, and several cytokeratin-positive bile ductules are seen in the peripheral portion of the tumor (b, $\times 200$; arrow). 